\title{
A FORMAÇÃO INICIAL DE PROFESSORES PARA A EDUCAÇÃO ESPECIAL NA PERSPECTIVA DA TEORIA DA SUBJETIVIDADE
}

\author{
THE INITIAL FORMATION OF TEACHERS FOR SPECIAL \\ EDUCATION FROM THE PERSPECTIVE OF THE THEORY OF \\ SUBJECTIVITY
}

Ana Valéria Marques Fortes Lustosa

Pós-doutora, Universidade Federal de São Carlos- UFSCar. São Carlos, São Paulo Professora Associada da Universidade Federal do Piauí- UFPI, PI, Brasil.

avfortes@gmail.com

\author{
D Enicéia Gonçalves Mendes \\ Pós-doutora, Universidade de Salamanca- USAL. Salamanca, Espanha. \\ Professora Titular da Universidade Federal de São Carlos-UFSCar. SP, Brasil. \\ eniceia.mendes@gmail.com
}

\begin{abstract}
Resumo: A formação de professores tem sido foco de distintas pesquisas que buscam elucidar sua organização no contexto brasileiro, tendo em vista os complexos impasses educacionais de um país com dimensões continentais, os interesses diversos de múltiplos setores da sociedade, bem como as demandas reais existentes. No caso da educação especial, essa situação é ainda mais intrincada e de difícil resolução. Este estudo, na perspectiva da teoria da subjetividade de Fernando González Rey, buscou compreender os processos subjetivos constituídos por graduandos de Licenciatura em Educação Especial no contexto da formação inicial. Quanto ao método, trata-se de um estudo de caso, sendo que a análise é do tipo construtivointerpretativa, tendo por base a epistemologia qualitativa. Os resultados apontam que o curso de licenciatura tem impactos sobre a subjetividade individual e social dos estudantes, com consequências benéficas para a inclusão escolar e para o público-alvo da educação especial.
\end{abstract}

Palavras-chave: Educação especial. Formação inicial. Subjetividade.

Abstract: The training of teachers has been the focus of different researches that seek to elucidate their organization in the Brazilian context, given the complex educational impasses of a country with continental dimensions, the diverse interests of multiple sectors of society, as well as the existing real demands. In the case of special education, this situation is even more intricate and difficult to solve. This study, from the perspective of Fernando González Rey's theory of subjectivity, sought to understand the subjective processes constituted by undergraduate students in Special Education in the context of initial training. As for the method, this is a case study, and the analysis is of the constructive-interpretative type, based on qualitative epistemology. The results show that the undergraduate course has impacts on the individual and social subjectivity of the students, with beneficial consequences for the school inclusion and the target audience of special education.

Keywords: Initial formation. Special education. Subjectivity.

\section{Para citar - (ABNT NBR 6023:2018)}

LUSTOSA, Ana Valéria Marques Fortes; MENDES, Enicéia Gonçalves. A formação inicial de professores para a educação especial na perspectiva da teoria da subjetividade. Eccos - Revista Cientifica, São Paulo, n. 54, p. 1-16, e8758, jul./set. 2020. Disponível em: https://doi.org/10.5585/eccos.n54.8758. 


\section{Introdução}

A formação de professores é um tema sempre em evidência no Brasil, pois, até os dias atuais, não foi possível equacionar os complexos impasses educacionais de um país com dimensões continentais, os interesses diversos de múltiplos setores da sociedade, bem como as demandas reais existentes. No âmbito da educação especial, não obstante os inúmeros documentos, leis, decretos, resoluções e portarias que delineiam um avanço efetivo nas últimas décadas, esse estado de coisas é ainda mais intricado e de difícil resolução.

A formação inicial nas licenciaturas, em particular, consiste em relevante uma etapa do desenvolvimento profissional, uma vez que produz efeitos duradouros nos indivíduos. As dificuldades se apresentam quando se percebe que incontáveis problemas permanecem sem resposta, tais como: a desvalorização da profissão que resulta em desinteresse e desmotivação dos jovens para atuar na docência; a carência de uma política nacional voltada especificamente para essa etapa e que busque articular qualidade, compromisso e observância ao disposto na legislação; adoção de currículos sistematizados e que integrem teoria e prática, aliados a estágios que possibilitem experiências ricas, avaliação efetiva e apoio institucional (GATTI, 2014).

Além disso, na atualidade, nota-se uma ênfase na formação continuada e a distância, com um aumento nas matrículas em instituições privadas, sem, contudo, observar-se modificação nos currículos que tendem a conservar o modelo presencial, sem adequação às novas tecnologias nos cursos a distância e, consequentemente, sem oferecer as condições necessárias tanto no que diz respeito ao aspecto tecnológico, quanto às formas de aprender, além da precária formação de tutores para atuar junto ao alunado. Outro aspecto a ser considerado se refere aos educandos que optam pelos cursos de licenciatura, haja vista que os estudos indicam que, de modo geral, são difíceis as condições sociais em que estes vivem (GATTI, 2014).

Quando se considera a formação nas licenciaturas em relação à educação especial, percebe-se que esta tende a manter, nos ordenamentos jurídicos, nas diretrizes do Ministério da Educação, nas alternativas proporcionadas por estados e municípios, a mesma ênfase na técnica em si mesma, com a finalidade de controle social, em detrimento da consistência teórica. Desse modo, os cursos não formam professores para refletir sobre a sua prática, mas os fundamentam para a resolução de problemas que permanecem insolúveis, sem uma alteração na forma de se viver a docência e de se estruturar a escola. Assim, e de modo geral, os cursos não fundamentam os futuros professores para atuar nessa área (SIMÕES; GIOVINAZZI JUNIOR, 2017). 
Observa-se que a formação de professores no campo da educação especial tem sido objeto de distintas pesquisas que buscam esmiuçar como se dá (i) a formação inicial (TAVARES, SANTOS, FREITAS, 2016), seja a partir do curso de Pedagogia (BRAGA, 2009), seja em relação às licenciaturas de modo geral (FREITAS, MOREIRA, 2011; VITALIANO, 2007); (ii) a formação continuada e a distância (MENDES, CABRAL, D’AFFONSECA, CALHEIROS, 2015; CAMPOS, MENDES, 2015); (iii) os fatores que a constituem (DIAS, ROSA, ANDRADE, 2015); (iv) a legislação que a determina (THESING, FERRAZ, MEDEIROS, COSTAS, 2017); (v) a avaliação (POSSA, NAUJORKS, SILVA, 2012); (vi) o currículo (GIVIGI, ALCÂNTARA, DOURADO, PEIXOTO, SILVA, 2017; MAGALHÃES, SOARES, 2016); (vii) as políticas públicas concernentes (PLETSCH, 2009; KASSAR, 2012; GARCIA, 2013; MICHELS, LEHMKUL, 2015). Ademais, em alguns casos, busca-se estabelecer comparações entre o Brasil e outros países (GREGUOL, GOBBI, CARRARO, 2013).

Pode-se perceber que a educação especial trata-se de uma área transversal, a qual demanda diferentes olhares para ser compreendida em sua amplitude, uma vez que envolve distintos segmentos da sociedade. Por essa razão, os estudos empreendidos procuram averiguar a oferta de disciplinas, o currículo e as formas como essa formação se processa. Seguindo esse viés, a pesquisa desenvolvida por Simões (2016 apud SIMÕES; GIOVINAZZI JUNIOR, 2017) aponta que, de modo geral, não há, nas licenciaturas, não mais do que uma ou duas disciplinas, prevalecendo, por força de lei, a Libras, a única disciplina regulamentada, não obstante a lei 10.098 de 2000, a qual determina que se estabeleçam condições para atender a todas as deficiências

De igual modo, Campos e Mendes (2015), em relação às licenciaturas que ofertavam cursos de licenciatura a distância sobre Educação Inclusiva, concluíram, em estudo, que ainda é escasso o número de universidades públicas e privadas que formam o professor para atuar no processo inclusivo, sendo que as que o fazem, de modo geral, estão prioritariamente localizadas nas regiões Sul e Sudeste. Aproximadamente 20\% dos cursos pesquisados não fazem menção à educação especial em seus quadros, ou seja, cerca de um quinto não tem sequer uma disciplina sobre esse campo, o que denota a contradição existente entre o que proclama a legislação (Portaria n. ${ }^{\circ} 1.793 / 1994$ e Decreto n. ${ }^{\circ} 5.626 / 2005$ ) e a realidade.

Apesar dessa constatação, o estudo de Campos e Mendes (2015) apontou também que as 108 instituições que ofertavam cursos de especialização a distância na área o faziam, preferencialmente, sobre educação Especial/Inclusiva ou em Libras, além de outros temas, de modo que foram encontrados 64 (sessenta e quatro) cursos, dos quais $83 \%$ são ofertados por 
instituições privadas. Quanto à formação continuada e considerando um total de 166 (cento e sessenta e seis) universidades investigadas, constatou-se que há cursos de extensão ofertados em 28 (vinte e oito) instituições privadas e em 24 (vinte e quatro) públicas. Já os cursos de aperfeiçoamento são oferecidos em 37 (trinta e sete) instituições (equivalendo um total de 22\%), sendo 34 (trinta e quatro) públicas e 3 (três) privadas.

Outros autores (CHACON, 2004; FREITAS; MOREIRA, 2011) também constataram a ausência de conteúdos na área de educação especial na formação de licenciandos. Essa situação constitui uma questão séria, que produz hiatos na formação e dificulta prospectivas positivas a esse respeito. Isso evidencia que a política tem privilegiado a formação continuada e a distância, no que respeita à formação de professores para atuar em contextos inclusivos, preterindo cursos de licenciatura de longa duração que poderiam proporcionar uma melhor atuação junto aos alunos do público-alvo da educação especial - PAEE.

Quando se discute como deve ser realizada a formação de professores para atuar na educação especial, Saviani (2009), por exemplo, considera que esta é uma questão que permenece "em aberto", pois, embora o curso de Pedagogia pudesse se constituir nesse espaço, as Diretrizes Curriculares Nacionais do curso abordam o tema apenas duas vezes e de forma tangencial. $\mathrm{O}$ autor acrescenta que:

Considerada a complexidade do problema inerente a essa modalidade [...] será necessário instituir um espaço específico para cuidar da formação de professores para essa modalidade de ensino. Do contrário essa área continuará desguarnecida e de nada adiantarão as reiteradas proclamações referentes às virtudes da educação inclusiva que povoam os documentos oficiais e boa parte da literatura educacional nos dias de hoje (SAVIANI, 2009, p. 253).

De acordo com Givigi et al. (2017, p. 51), os cursos voltados para a formação de professores para atuar na educação especial não são bem sucedidos em razão dos seguintes fatores:

são baseados em módulos e etapas a percorrer, e em modelos a reproduzir; que são
planificados por serviços centrais; que trabalham numa relação de poder vertical do
formador sobre o professor; que a formação continuada não faz relação com a
formação inicial; que quer tratar a prática pedagógica como se fosse a transmissão de
"novas" técnicas. [...] além disso esses programas reforçaram o alheamento e a
alienação de grande número de professores (GIVIGI et al., 2017, p. 51 ).

Além das dificuldades elencadas, destaca-se a proliferação de cursos que não respeitam a singularidade individual e social dos professores, singularidades essas que perpassam todas as questões apresentadas anteriormente, tendo em vista que o elemento comum é o homem em toda a sua complexidade, em sua relação com o meio no qual está inserido e do qual sofre influência e, por sua vez, influencia. Logo, diante dessa constatação, não é possível negar que os processos subjetivos atravessam a educação especial, seja singularmente (o sujeito), seja 
coletivamente (a sociedade), promovendo ordenações e reorganizações em função da experiência vivenciada por cada um, haja vista o caráter gerador da subjetividade e a participação ativa dos sujeitos. A inclusão escolar, assim, constitui-se, em toda a sua extensão, por aspectos subjetivos que nem sempre são percebidos. São estes aspectos que, como afirmam Gomes e González Rey (2007, p. 408), "há muito delimitam e estigmatizam esses alunos” em alguns casos e, em outros, promovem seu desenvolvimento.

A teoria da subjetividade na perspectiva cultural-histórica de Fernando González Rey (2002a; 2003; 2005b; 2011; 2017) possibilita explorar as intricadas teias em que se desenvolve a formação de professores para atuar em contextos inclusivos, uma vez que suplanta os aspectos puramente objetivos, vistos de um ponto de vista determinista e linear. Ao considerar que sujeito e sociedade estão de tal forma imbricados na processualidade do processo de formação, de modo dialético e complexo, em função dos impactos que exercem mutuamente na subjetividade individual e na subjetividade social, o autor extrapola as explicações reducionistas, ainda que expressivas, ampliando-as para que se leve em conta não somente o contexto, mas o sujeito que dele faz parte. A subjetividade para González Rey (2017, p. 182):

não é um fenômeno intrapsíquico, mas uma característica de todo processo humano, realidade e sistema. Subjetividade é tão simultaneamente intrínseca ao funcionamento social quanto aos processos individuais singulares. Subjetividade é um nível psicológico diferenciado da existência cultural dos humanos (tradução nossa) ${ }^{1}$.

Compreende-se, portanto, que a subjetividade perpassa todos os processos sociais e individuais existentes no âmbito cultural. Enquanto produção simbólica e emocional gera sentidos e configurações subjetivas em decorrência das experiências vivenciadas, as quais, segundo González Rey (2017, p. 182, tradução nossa), "são produções subjetivas e não reflexos ou assimilação de fatos, influências ou objetos externos"2.

Nesse movimento, emoções e processos simbólicos integram-se de múltiplas formas, interminavelmente, de modo a gerar sentidos subjetivos, os quais constituem a unidade simbólico-emocional da subjetividade. Nesse fluxo, processos simbólicos e emoções evocam um ao outro recursivamente, sem que um se torne a causa do outro.

Há, nos sentidos subjetivos, uma característica que González Rey e Martínez (2017) denominam de plasticidade, a partir da qual compreendem que o comportamento, as ações ou mesmo uma emoção que domine o sujeito não estão reduzidos a uma única causa, pois decorrem de produções diante do que é vivido. Assim, não há causas externas. Os sentidos representam,

\footnotetext{
${ }^{1}$ Advances in subjectivity from a cultural-historical perspective: unfoldings and consequences for cultural studies today. In: FLEER; M.; VEROSOV, N.; GONZÁLEZ REY, F. (Eds.). Perezhivanie, emotions and subjectivity: advancing Vygotsky's legacy. Singapore: Springer, 2017, pp.173-193. 
portanto, os momentos vividos no passado e no presente pelo sujeito, nos distintos espaços sociais, e que, em seu movimento ininterrupto, constituem as configurações subjetivas.

Já as configurações subjetivas não representam a mera soma de sentidos subjetivos, mas sim uma forma de auto-organização geradora de sentidos, sem a qual estes se desenvolveriam em um fluxo caótico e desordenado, pois se desdobram em outros e coincidem com outros, originando uma rede subjetiva complexa. São as configurações subjetivas que geram as percepções, fantasias, medos, pensamentos, emoções e percepções dominantes, bem como outros estados subjetivos que caracterizam qualquer função psicológica. Elas são inseparáveis da ação (GONZÁLEZ REY, 2017).

As configurações estão em constante movimento, podendo engendrar conflitos com outras nesse processo, dando origem a novas configurações. É no movimento de assumir posições e decisões que surge o sujeito, outro conceito essencial na teoria da subjetividade. É o sujeito que, a partir das suas ações, abre novas vias de subjetivação, de modo criativo, mas que nem sempre se mostra em suas ações e nos espaços sociais pelos quais transita. O sujeito apresenta um caráter emocional e "seus atos se configuram subjetivamente, permitindo-lhe a abertura de um espaço de subjetivação que se confronta com os espaços normativos em que atua [...]. Logo, o sujeito pode ser subversivo também (GONZÁLEZ REY; MARTÍNEZ, 2017, p. 75).

Por fim, é importante compreender que a subjetividade se caracteriza por ser individual, definida pelos processos individuais, configurações subjetivas e sentidos subjetivos que emergem em sujeitos concretos. A subjetividade constitui-se também como social, pois os sujeitos "vivem em complexas redes sociais resultantes de discursos sociais, representações sociais e outras produções sociais simbólicas que são configuradas de diferentes maneiras nas configurações subjetivas do sistema de relações imediatas deles" (GONZÁLEZ REY, 2017, p. 186, tradução nossa). Estas redes constituem a subjetividade social, que se evidencia em grupos informais ou em instituições e que inclui produções simbólicas, as quais podem estar relacionadas a outros espaços sociais. Em outras palavras, a subjetividade social está presente em todos os espaços sociais que constituem a sociedade, em complexas configurações subjetivas.

Nesse sentido, o contexto universitário, assim como outros espaços socioculturais, afeta, de forma distinta, cada um dos educandos, tendo em vista que as experiências são subjetivadas de modo singular por cada um, na perspectiva destacada por González Rey (2006) e Mitjáns Martínez (2014). 
Dessa maneira, pode-se questionar: Como a formação específica influencia a subjetividade individual de futuros professores de educação especial em um contexto extremamente favorável, no qual a subjetividade social é permeada por valores e crenças firmemente estabelecidas quanto aos direitos desses sujeitos? Como são afetados os graduandos quando em contato frequente com educandos do público-alvo da educação especial? Quais os processos subjetivos que se constituem em um ambiente no qual predomina a aceitação e a nãodiscriminação da diversidade?

Este estudo, portanto, buscou compreender, na perspectiva da teoria da subjetividade, os processos subjetivos constituídos por graduandos de Licenciatura em Educação Especial no contexto da formação inicial.

\section{Método}

Esta pesquisa respalda-se na Epistemologia Qualitativa, proposta por González Rey (1997; 2002b; 2005b), para o estudo da subjetividade, de modo a articular o empírico e a construção teórica do pesquisador. A Epistemologia Qualitativa ancora-se em três princípios norteadores, quais sejam: (i) o caráter construtivo-interpretativo do conhecimento, (ii) a relevância do diálogo para a pesquisa e (iii) a definição do singular como instância legítima da produção de conhecimento científico.

O estudo foi desenvolvido em uma universidade situada na região Centro-Leste do estado de São Paulo, mais especificamente em um curso de Licenciatura em Educação Especial (PPGEES), que atende a alunos de distintas partes do país e de outras regiões do estado.

Após o convite, quatro formandas aceitaram participar do estudo de caso, entretanto somente duas permaneceram até o final, pois houve greve naquele período, além dos inúmeros compromissos relacionados ao estágio e ao trabalho de conclusão do curso, entre outros contratempos que impediram uma adesão maior. Nesse artigo, contudo, será discutido unicamente um dos estudos de caso. A participante tinha, à época, 42 anos, era casada e tinha filhos.

Adotou-se como instrumentos da pesquisa o completamento de frases, documento escrito adaptado de González Rey e Martínez (1989) e composto por 58 frases incompletas destinadas à identificação de indicadores relevantes, assim como voltado para a construção de hipóteses em relação a aspectos da subjetividade; as dinâmicas conversacionais, o conflito de diálogos, uma composição (O significado do curso de Licenciatura em Educação Especial na minha vida: ontem, hoje e amanhã) e um caso de ensino, este último adaptado da tese de Duek 
(2011). Esses instrumentos, em conjunto, permitiram a construção das informações segundo os preceitos da Epistemologia Qualitativa. O estudo foi submetido ao Comitê de Ética e a pesquisa só foi iniciada após a sua aprovação.

Inicialmente foram realizadas conversas informais com as participantes, de modo a constituir o cenário da pesquisa. O completamento de frases foi preenchido e discutido em três momentos informais. Posteriormente, foram aplicados o conflito de diálogos e o caso de ensino. Todos os instrumentos foram seguidos por dinâmicas conversacionais, de modo a possibilitar a construção dos indicadores e, posteriormente, a partir desses, as hipóteses. Estas emergiam em função da construção teórica, de modo não linear e através das compreensões e construções da pesquisadora.

A análise das informações do estudo de caso promoveu o entendimento da subjetividade individual da participante em sua história de vida peculiar e, simultaneamente, da subjetividade social presente nos contextos nos quais vivia e sob os quais elaborou suas impressões, percepções, sentimentos, anseios, vivências etc. Na Epistemologia Qualitativa, a análise se dá em um processo contínuo de interpretação e elaboração teórica.

\section{Resultados e discussão}

Os resultados serão apresentados a partir da análise de eixos do estudo de caso, de modo a compreender os processos subjetivos constituídos pela graduanda em Licenciatura em Educação Especial no contexto da formação inicial; assim como conhecer suas concepções acerca da inclusão escolar e identificar como a formação inicial era subjetivada por ela e o impacto na sua atuação em contextos inclusivos com alunos público-alvo da educação especial.

A análise consiste em um movimento construtivo-interpretativo, no qual se desvelam os processos e configurações subjetivas mais relevantes na subjetividade dos participantes. Tratase de uma construção teórica que envolve o pesquisador nos meandros das produções subjetivas dos sujeitos relacionadas à cultura, aos espaços sociais nos quais estes se inserem e as emoções que desenvolvem de modo singular e complexo.

\subsection{Saindo da Caverna: a família como configuração subjetiva}

Inicialmente faz-se necessário situar a participante como sujeito situado em um contexto social e histórico. Atualmente, ela é casada, tem quatro filhos e voltou a estudar apenas após a última filha completar 3 anos de idade. Em uma analogia com a alegoria da caverna de Platão, 
vê-se, após o nascimento do primeiro filho, despertar de um longo período em que sofria em função de problemas que enfrentou na infância, razão pela qual desenvolveu baixa autoestima. Em suas palavras:

\begin{abstract}
"Antes eu achava que eu não tinha valor nenhum e depois do filho é como se alguém abrisse as janelas, me tirasse da caverna. Aí eu olhei o mundo! Até ali, eu só via sombras dentro da caverna e depois que meu filho nasceu, eu saí da caverna e enxerguei o mundo. A maternidade tem esse peso para mim. É o peso da libertação. A maternidade me deu esse presente, ela me mostrou que a relação que eu tive com a minha mãe ali na infância, não era assim, ser mãe e ser filho, e transformou uma mágoa que vinha da rejeição em piedade por uma mãe que não pôde, que não viveu a maternidade como eu passei a viver".
\end{abstract}

Considera-se que a participante apresenta a família como uma configuração subjetiva que influencia, modifica, aperfeiçoa e mobiliza recursos subjetivos essenciais que possibilitam a reflexividade e o desenvolvimento de autoconhecimento, de maneira que esta está presente em distintos instrumentos e nas dinâmicas conversacionais, como um indicador que permite gerar a hipótese de superação e de busca pelo autoconhecimento. Essa compreensão decorre da constatação de que há, em sua fala, conteúdos simbólicos e emocionais que se entrelaçam, de forma a articularem não apenas as emoções, mas os pensamentos, a imaginação e as ações que realiza a partir das vivências nesse âmbito (GONZÁLEZ REY; MARTÍNEZ, 2017).

Esta configuração se mostra tão intensa que ela afirma: "Quando o Theo ${ }^{3}$ nasceu, quando eu percebi que a vida podia ser diferente, eu comecei a buscar por esse autoconhecimento, eu comecei a olhar pra vida e entender que poderiam existir outras verdades". No completamento, a família aparece em distintas sentenças: "Eu mãe; Minha maior preocupação filhos; Sempre que posso passeio e brinco com meus filhos; Amo a maternidade; O passado me ensinou; A família é o círculo mais íntimo; Quando eu era criança, passado; Meu maior prazer ser mãe". Mais do que superar, ser mãe possibilitou que ela fizesse diferente, pensasse de outra forma, sanasse as mágoas e continuasse em frente, de forma a viver uma vida mais consciente e plena.

A apresentação dessas sentenças e a discussão sobre essa configuração é relevante por permitir compreender a participante como sujeito que agiu e reagiu a um contexto desfavorável, singularizando-o de maneira simbólico-emocional em experiências pessoais que a permitiram suplantar esses momentos de sua história individual.

Em outro momento, percebe-se a vinculação da família com os processos subjetivos desenvolvidos em relação ao curso de educação especial, pois ela comenta que:

"O aprendizado do curso veio para minha vida, veio para a vida dos meus filhos, da minha família, porque é um olhar de outro lugar para uma população excluída. Então

\footnotetext{
${ }^{3}$ Todos os nomes referem-se a pseudônimos, com vistas a preservar o anonimato.
} 
é um formar o meu filho para conviver com a diferença, que talvez se eu não estivesse no curso, apesar de respeitar a diferença, eu não teria conhecimento para formar os meus filhos para conviver com a diferença".

A reapresentação da configuração família em outros âmbitos da vida da participante é um exemplo do que González Rey (2017) assevera quanto à capacidade das configurações subjetivas integrarem distintos sentidos subjetivos relativos a estados, valores, vivências passadas e interesses profissionais, em uma experiência única, uma unidade. Observa-se que o que é relevante para a participante se expressa em outras áreas da sua trajetória de vida, como um desdobramento que se mostra dominante. É o que se vê no excerto acima.

Assim, observa-se que a formação se faz tão relevante que extrapola o âmbito da universidade, inserindo-se na sua experiência familiar. No próximo subtópico, ver-se-á como essa se revela em relação à formação da participante e como está configurada na sua subjetividade, alicerçando processos subjetivos que se manifestam em sua expressão e nas entrelinhas do dito e não dito.

\subsection{Aprendizagem como produção subjetiva}

No que diz respeito ao curso de Licenciatura em Educação Especial, percebe-se que este tem uma importância vital para a participante, aliado ao desejo de aprender em todos os momentos. Esse anseio pelo conhecimento se mescla com o interesse em contribuir para a sociedade, de modo que a formação se torna meio e fim para esse objetivo. Considera-se que se trata de um movimento recursivo, no qual, à medida que aprende, modifica espaços e relações, como, por exemplo, (i) o convívio com os filhos, que se transformam em multiplicadores, (ii) a relação com as professoras nos estágios realizados em colaboração e (iii) as mudanças alcançadas no desenvolvimento dos alunos PAEE.

A produção subjetiva da aprendizagem, desse modo, incorpora outros momentos da vida da participante da pesquisa em complexas respostas emocionais decorrentes dos processos simbólico-afetivos presentes nas relações sociais vivenciadas por ela (GONZÁLEZ REY, 2017), o que permite constatar a relevância da formação inicial no seu processo de desenvolvimento pessoal.

Observa-se a firme relação estabelecida entre a formação e o aprender no conflito de diálogos, no caso de ensino e no complemento, do qual se apresentam as seguintes sentenças: "Sinto-me feliz aprendendo; Queria saber mais sobre mim; Desejo sempre aprender; Como graduanda em educação especial, sinto-me realizada; Com frequência, reflito sobre como contribuir com o PAEE; Eu aprendo vivendo; A aprendizagem faz sentido quando posso usá-la; O curso de 
Licenciatura em Educação Especial é caminho; O que eu aprendo é útil para compartilhar; Sonho evoluir; Quando tenho dúvidas, estudo; Quando formada, desejo não parar de estudar; Mas não é só o aprender acadêmico, é um aprender viver; É um aprender com o outro".

Observa-se que as sentenças evocam uma condição subjetiva de permanente busca pela aprendizagem que se manifesta em distintos espaços da vida da participante, pois as ocasiões nas quais esse anseio se manifesta sempre se modificam.

Nesse processo, evidencia-se o aprender como produção subjetiva que constitui a participante como sujeito que aprende, cujas emoções envolvidas possibilitam e ampliam, de forma criativa e intencional esse processo, o qual se refere não somente ao aspecto cognitivo-intelectual, mas aos aspectos emocionais, imaginativos, culturais e sociais envolvidos (GONZÁLEZ REY, 2014).

Há uma clareza quanto a importância da formação inicial, mas não como algo estanque que pode possibilitar a resolução de todos os desafios que enfrenta. $\mathrm{Na}$ verdade, essa se constitui em processo que se faz inseparável do crescimento pessoal. Essa construção foi possível em razão das dinâmicas conversacionais que permitiram, através do diálogo, que a participante gerasse reflexões sobre sua atuação.

A formação, portanto, consolida-se na reflexão acerca dos indivíduos do público-alvo da educação especial, do sentimento de estar realizada e no compromisso e implicação com o trabalho com esse segmento da sociedade. É possível perceber a influência da subjetividade social, aqui representada por vivências da graduanda em distintos contextos, em particular no curso de licenciatura, bem como com as pessoas que dele fazem parte. Nesse sentido, a processualidade e a complexidade ultrapassam os aspectos meramente objetivos evidenciados na importância de um ambiente cultural e socialmente favorável ao outro diferente (GONZÁLEZ REY, 2017).

No caso de ensino, cogita acerca da pertinência de refletir sobre a sua prática, quando, ao se referir a uma das professoras que demonstra ter dúvidas se está no caminho certo, afirma que esse questionamento é o que mobiliza as professoras com quem trabalhou nos estágios, as quais se mostraram abertas a trabalhar nos moldes do ensino colaborativo, foco do curso em questão. A esse respeito comenta: 
"Eu vejo com muito respeito, principalmente quando a professora diz que busca acertar o caminho, quando reflete sobre a própria prática. Isso é digno de muito respeito! É um professor que tem humildade de dizer 'eu não sei'. Olhando para a realidade que a gente tem, para realidade que eu vivi no último ano de estágio em uma escola de periferia, numa sala de fase 5, com alunos de quinto ano e uma professora ainda preocupada em saber como ela pode fazer aquele aluno evoluir, eu acho desumano o sistema, porque ele cobra uma postura da professora, mas não dá instrumentos, não instrumentaliza essa professora, não dá condições de trabalho. E aí gera comentários do tipo: o aluno não aprende! Porque se ela disser qualquer outra coisa, ela vai dizer eu não fui capaz, eu sou culpada. Isso é muito pesado! É o sistema que faz isso. Não tem apoio para educação especial, não tem formação do gestor".

Nesse fragmento, distingue-se, de modo evidente, o que afirmam Saviani (2009), Givigi et al (2017) quanto à formação dos professores para atuar com alunos público-alvo da educação especial, pois esses docentes não se sentem preparados para atuar com esse tipo de alunado, ainda que, em muitos casos, desejem fazê-lo. Expõem, assim, o mérito do trabalho colaborativo desenvolvido por dois professores em sala de aula, possibilitando trocas essenciais e facilitando o processo de aprendizagem e desenvolvimento desse segmento.

Os sentidos subjetivos gerados no contexto da formação são fonte de emergência de novos estados subjetivos, expressos nas ações de aprender, compreender, não discriminar, ampliados pela atitude reflexiva.

\subsection{Incluir: nada menos que isso}

A compreensão do que significa a inclusão possibilita o desenvolvimento de valores e sentimentos morais, como o respeito e a indignação frente aos limites do sistema educacional. A aceitação da heterogeneidade representa a essência de uma visão mais ampla do que significa incluir de fato.

Nessa perspectiva, para a graduanda, o aluno público-alvo da educação especial é simplesmente o aluno, nem mais nem menos do que os outros, cujas necessidades devem ser conhecidas antes de qualquer outra ação (um aluno difícil não existe - completamento de frases). Desse modo, o educando é considerado como sujeito que aprende e, por essa razão, visto em sua singularidade e em função dos complexos processos simbólico-afetivos que apresenta. Isso traz implicações fundamentais para o trabalho pedagógico com esse alunado, pois o foco passa a ser não somente o intelecto, mas as emoções, a imaginação, os pensamentos, os medos, as fantasias e tudo o mais que constitui o sujeito (MITJÁNS MARTÍNEZ, 2014).

No conflito de diálogos, evidencia-se a compreensão da graduanda acerca do sistema educacional como em construção e os professores como parceiros, indicadores que demonstram 
a produção de novos sentidos subjetivos acerca do âmbito escolar, distintos dos que se costuma observar quando se pesquisa sobre a educação especial. Considera-se que o curso de licenciatura contribuiu enormemente para isso, pois funda-se em espaço cultural-histórico repleto de pessoas que pensam a educação especial de outro modo.

\section{Conclusões}

O estudo de caso apresentado lança luz sobre aspectos da formação inicial em educação especial que não estão presentes em outros estudos, pois aponta a extensão em que esta formação pode se manifestar na subjetividade social e individual dos sujeitos, tornando-os mais abertos à inclusão escolar, seguros quanto ao que deve ser realizado, criativos e reflexivos no trabalho pedagógico com o PAEE.

A Licenciatura em Educação Especial possibilitou o desenvolvimento dessa compreensão por se constituir em lócus em que o diálogo sobre o público-alvo da educação especial destoa do que predomina na sociedade como um todo e, embora possa haver vozes dissonantes, há um entendimento mais pertinente sobre quem são esses alunos.

A graduanda afirma, ao comparar o curso com a licenciatura em Pedagogia, o seguinte: "Eu acho que o que mais diferencia, o que mais promove é realmente a cultura de você saber que você está sendo formado para trabalhar com esse público". Considera-se, como afirma González Rey (2017, p. 183, tradução nossa), que as "instâncias sociais são simultaneamente sistemas subjetivos dentro dos quais a ação individual desdobra-se em muitos efeitos sociais, que, recursivamente, são também configurados nos indivíduos". Nesse sentido, as vivências sociais experienciadas no curso possibilitam um novo entendimento do que significa a inclusão, assim como propiciam a constituição de novos processos subjetivos.

Não se quer com isso generalizar o que foi revelado, pois isto iria frontalmente contra a proposta da teoria da subjetividade, uma vez que se reconhece que a experiência vivida se configura de formas distintas nos diferentes sujeitos, mas quer se ressaltar que a cultura influencia os sujeitos e é por eles constituída, em um processo que demanda toda a existência do ser humano e que se perpetua até o fim da sua existência.

Desse modo, acredita-se que as experiências no curso possibilitaram produções subjetivas relevantes que se mesclaram com a vida da participante, fazendo dela, efetivamente, um sujeito da inclusão. 


\section{Referências}

BRAGA, D.R. Formação inicial de professores e educação especial. Acesso em: 12. nov. 2016. Disponível em: http://32reuniao.anped.org.br/arquivos/trabalhos/GT08-5205--Int.pdf, 2009.

BRASIL. Ministério da Educação. Portaria n. ${ }^{\circ}$ 1.793, de dezembro de 1994. Brasília, 1994.

BRASIL. Decreto $n$. $^{\circ} 5.626$ de 22 de dezembro de 2005. Brasília, 2005. Disponível em: http://portal.mec.gov.br/seesp/. Acesso em: abr./2011.

CAMPOS, Mariana de Lima Isaac Leandro; MENDES, Enicéia Gonçalves. Formação de professores para a educação inclusiva em cursos à distância: um estudo de campo documental. Revista Cocar, Belém/Pará, Edição Especial, n.1, p. 209-227, 2015.

CHACON, Miguel Cláudio Moriel. Formação de Recursos Humanos em Educação Especial: resposta das universidades à recomendação da Portaria Ministerial n. ${ }^{\circ} 1.793$. Revista Brasileira de Educação Especial, Marília, v. 10, n. 3, p. 321-336, 2004.

DIAS, Marian Ávila de Lima; ROSA, Simone Conceição; ANDRADE, Patrícia Ferreira. Os professores e a educação inclusiva: identificação dos fatores necessários à sua implementação. Psicologia USP, São Paulo: v. 26, n. 3, pp. 453-463, 2015.

DUEK, Viviane Preichardt. Educação inclusiva e formação continuada: contribuições dos casos de ensino para os processos de aprendizagem e desenvolvimento profissional de professores. 349p. Tese (Doutorado em Educação). Universidade Federal do Rio Grande do Norte. Natal, 2011.

FREITAS, Soraia Napoleão, MOREIRA, Laura Ceretta. A universidade frente à formação inicial na perspectiva da inclusão. In: CAIADO, Kátia Regina Moreno; JESUS; Denise Meyrelles de; BAPTISTA, Cláudio Roberto. (Org.) Professores e educação especial: formação em foco. Porto Alegre: Mediação/CDV/FACITEC, 2011. v. 1, p. 65-73.

FREITAS, H. C. L. de. Formação de professores no Brasil: 10 anos de embate entre projetos de formação. Educ. Soc., Campinas, vol. 23, n. 80, setembro/2002, p. 136-167.

GARCIA, R. M. C. Política de educação especial na perspectiva inclusiva e a formação docente no Brasil. Rev. Bras. Educ., Rio de Janeiro, v. 18, n. 52, 2013, p. 101-119.

GATTI, B. A. Formação inicial de professores para a educação básica: pesquisas e políticas educacionais. Est. Aval. Educ., São Paulo, v. 25, n. 57, p. 24-54, jan./abr. 2014.

GIVIGI, R. C. do N.; et al. A construção curricular coletiva na formação de professores da educação especial. Revista Contrapontos - Eletrônica, Itajaí, v. 17, n. 1, 2017.

GOMES, C. GONZÁLEZ REY, F. Inclusão Escolar: Representações compartilhadas de profissionais da educação acerca da inclusão escolar. Psicologia Ciência e Profissão, 2007, 27 (3), 406-417. 
GONZÁLEZ REY, F. L. Sujeto y subjetividad: una aproximación histórico-cultural. México: Thomson Editores, 2002a.

GONZÁLEZ REY, F. L. Sujeito e subjetividade: uma aproximação histórico-cultural. São Paulo: Pioneira Thomson Learnig, 2003.

GONZÁLEZ REY, F. L. (Org.). Subjetividade, complexidade e pesquisa em psicologia. São Paulo: Pioneira Thomson Learnig, 2005a.

GONZÁLEZ REY, F. L. Subjetividade e saúde: superando a clínica da patologia. São Paulo: Cortez, 2011.

GONZÁLEZ REY, F. L. A imaginação como produção subjetiva: as ideias e os modelos da produção intelectual. O sujeito que aprende: diálogos entre a psicanálise e o enfoque histórico-cultural. Albertina Mitjáns Martínez; Patrícia Álvares (Orgs.) Brasília: Liber Livro, 2014.

GONZÁLEZ REY, F. L. Advances in subjectivity from a cultural-historical perspective: unfoldings and consequences for cultural studies today. In: FLEER; M.; VEROSOV, N.; GONZÁLEZ REY, F. (Eds.). Perezhivanie, emotions and subjectivity: advancing Vygotsky's legacy. Singapore: Springer, 2017, p.173-193.

GONZÁLEZ REY, F. L. Pesquisa qualitativa e subjetividade: os processos de construção da informação. São Paulo: Pioneira Thomson Learning, 2005 b.

GONZÁLEZ REY, F. L. Pesquisa qualitativa em psicologia: caminhos e desafios. São Paulo: Pioneira Thomson Learning, 2002b.

GONZÁLEZ REY, F. L. Social and individual subjectivity from an historical cultural standpoint. Critical Social Studies, v. 9, n. 2, p. 10, 2007.

GONZÁLEZ REY, F. L. Epistemología cualitativa y subjetividad. São Paulo: Educ, 1997.

GONZÁLEZ REY, F. L..; MARTÍNEZ, A. M. Subjetividade: teoria, epistemologia e método. Campinas, SP: Editora Alínea, 2017.

GONZÁLEZ REY, F. L. (1989). La personalidad: su educación y desarrollo. La Habana: Ed. Pueblo y Educación.

GREGUOL, M.; GOBBI, E.; CARRARO, A. Formação de professores para a educação especial: uma discussão sobre os modelos brasileiro e italiano. Rev. Bras. Ed. Esp., Marília, v. 19, n. 3, p. 307-324, jul.-set., 2013.

KASSAR, M. C, M. Educação especial no Brasil: desigualdades e desafios no reconhecimento da diversidade. Educação \& Sociedade, Campinas, v. 33, n. 120, p. 833-849, 2012.

MAGALHÃES, R.C.B.; SOARES, M.T.N. Currículo escolar e deficiência: contribuições a partir da pesquisa-ação colaborativo-crítica. Cad. Pesq. São Paulo, v.46 n.162 p.1124-1147 out./dez. 2016. 
MITJÁNS MARTÍNEZ, A. O lugar da imaginação na aprendizagem escolar: suas implicações para o trabalho pedagógico. O sujeito que aprende: diálogos entre a psicanálise e o enfoque históricocultural. Albertina Mitjáns Martínez; Patrícia Álvares (Orgs.) Brasília: Liber Livro, 2014.

MENDES, E. G.; et al. A formação dos professores especializados segundo os pesquisadores do observatório nacional de educação especial. Educação e Fronteiras On-Line, Dourados/MS, v.5, n.13, pp. 84-95, maio/ago., 2015.

PLETSCH, M. D. A formação de professores para a educação inclusiva: legislação, diretrizes políticas e resultados de pesquisas. Educar em Revista, Curitiba, n. 33, p.143-+156, 2009.

POSSA, L. B; NAUJORKS, M. I.; SILVA, G. M. R. Matizes do discurso sobre avaliação na formação de professores da Educação Especial. Revista Educação Especial, Santa Maria, RS, v. 25 , n. 44 , p. 465-482, 2012.

SAVIANI, D. Formação de professores: aspectos históricos e teóricos do problema no contexto brasileiro. Rev. Bras. Educ., Rio de Janeiro, v. 14 n. 40 jan./abr., p. 143-155, 2009.

SIMÕES, M. C.D.; GIOVANAZZI JUNIOR, C.A. Os limites da formação docente e a educação das pessoas com deficiência nas licenciaturas. Rev. FAEEBA - Ed. e Contemp., Salvador, v. 26, n. 50, p. 49-61, set./dez. 2017

TAVARES, L. M. F. L.; SANTOS, L.M. M. dos.; FREITAS, M. N. C. A Educação Inclusiva: um estudo sobre a formação docente. Rev. Bras. Ed. Esp., Marília, v. 22, n. 4, p. 527-542, 2016.

THESING, M. L. C.; et al. Formação de professores em educação especial no "Plano Nacional de Educação Proposta da Sociedade Brasileira" de 1997. Em Aberto, Brasília, v. 30, n. 98, p. 133-149, jan./abr. 2017.

VITALIANO, C.R. Análise da necessidade de preparação pedagógica de professores de cursos de licenciatura para inclusão de alunos com necessidades educacionais especiais. Rev.Bras. Ed. Esp., Marília, 2007, v.13, n.3, p.399-414. 